\title{
FINE RESOLUTION IMAGERY AND GIS FOR INVESTIGATING THE MORPHOLOGICAL CHARACTERISTICS, AND MIGRATION RATE OF BARCHAN DUNES IN THE ERG SIDI MOUSSA DUNEFIELD NEAR IN- SALAH (ALGERIA)
}

\author{
Nouar BOULGHOBRA ${ }^{1,2}$, Hadda DRIDI ${ }^{1}$
}

DOI: 10.21163/GT_2016.112.02

\begin{abstract}
:
This research interested in determining the morphological characteristics and barchan movement, within the Erg Sidi Moussa dunefield near In-Salah (central Algerian Sahara). Based on field measurements, 12 individual barchan dunes have been subjected to morphological investigation, results showed that normal variety is more prominent compared to slim, pudgy and fat forms, according to the classification of Bourke and Goudie (2009). Based on fine resolution imagery and GIS, the rate and trend of barchan dune migration has been accurately measured. From Jan. 5, 2013 to Feb. 3, 2016, the average of movement rate was estimated to be $14 \mathrm{~m} / \mathrm{yr}$ and movement angle to be about $64^{\circ}$, in well accordance with the prevailing wind direction and the sand transport trend. Results revealed as well that the barchan dune movement is inversely proportional to the dune dimensions, meaning that dunes of smallest height and width are moving much faster than more-sized ones. Due to its position downwind, In-Salah city is facing a real risk of accumulating sand and mobile dunes. To mitigate damages, it is highly recommended that dune fixation techniques be realized upwind, and that the risk management be considered for future planning projects.
\end{abstract}

Key-words: Barchan dune, Morphology, Satellite imagery, GIS, Dune migration

\section{INTRODUCTION}

Sand dunes are defined as the accumulation of windblown sand deposited by the wind, they are generally composed of quartz and feldspar grains with a diameter ranging from 0.062 to $2 \mathrm{~mm}$ (Lancaster, 2009; Tsoar, 2001).

The classification of sand dunes is mainly depending on three factors: morphology (McKee, 1979), prevailing wind regime and wind environment energy (Fryberger \& Dean, 1979) and the dune mobility (Tsoar, 2004); three distinct types could be identified: first, accumulating dunes which consist mainly of star dunes associated with complex wind regime; second, elongating dunes corresponding to linear dunes occurring under bi-modal wind regime and, finally, the migrating dunes involving crescent shaped dunes associated with uni-modal wind regime, these include transverse dune, barchanoid ridge and barchan dune as the final stage of their development, it corresponds to an individual dune presenting a concave slipeface and two elongating horns which extend downwind; barchan dune can migrate long distances with no or minor changes of form and dimensions (Long \& Sharp, 1964; Sauermann et al., 2000, Lancaster, 2009), and their accumulation could endanger urban sites and socioeconomic infrastructures (Khalaf \& Al-Ajmi, 1993; Boulghobra, Hadri

\footnotetext{
${ }^{1}$ University of El-Hadj Lakhder, Faculty of Sciences, 05000 Batna, Algeria boulghobra.n@gmail.com, hadda.dridi@gmail.com

${ }^{2}$ Scientific and Technical Research Center on Arid Regions (CRSTRA), 30200 Touggourt, Algeria
} 
\& Bouhana, 2014; Boulghobra, 2016). Thus, the accurate assessment of barchan movement rate and direction is required in regional planning as well as in the choice of the socioeconomic installation sites; their migration aptitude depends on several factors such as the climate (aridity, wind strength and direction), the vegetation cover rate, the amount of sand drift and topography. Besides, the barchan morphology and dimensions could be a prominent factor in determining its movement rate (Finkel, 1959; Long\&Sharp, 1964; Khalaf \& El-Ajmi, 1993; Sauermann et al., 2000; Al-Dousari \& Pye, 2005; Hamdan, Refaat \& Abdel Wahed, 2016).

Long-term field monitoring and mapping of the barchan dune migration is among the most difficult and expensive tasks in quantitative geomorphology. However, aerial photography, remotely sensed data and GIS based approaches could be a powerful tool for understanding and modeling the land process in arid regions (e.g., Bouhata \& Kalla, 2014). Besides, fine resolution imagery of significant time-series length is a reliable resource in accurately measuring, surveying and mapping the barchan movement and direction (e.g. Hamdan, Refaat \& Abdel Wahed, 2016; Boulghobra, 2016).

The Erg Sidi Moussa dunefield is located in the southern Algerian Sahara; it occupies the upwind position (north east) of the In-Salah agglomeration. This small dunefield is recognized as an environment of high wind energy and strong uni-modal wind regime, associated with mobile barchan dunes (Verlaque, 1958; Breed et al., 1979; Warren \& Knott, 1979, Boulghobra, Hadri \& Bouhana, 2014; Boulghobra, 2016). As a consequence, transported sands and migrating barchans constitute real risk sources of sand accumulation on palm-dates, built areas as well as socioeconomic infrastructures.

This research aims to: (1) investigate the main morphological features characteristics of the Erg Sidi Moussa barchan dunes based on in-situ measurements; (2) assess the barchan dunes migration rate and direction using bi-temporal fine resolution imagery and GIS, and; (3) evaluate the risk of encroaching sands and migrating barchans in the area of In-Salah.

\section{MATERIALS AND METHODS}

\subsection{Study area}

Within the Sahara desert, In-Salah is located between the $27^{\circ} 07^{\prime}-27^{\circ} 16^{\prime}$ north and the longitudes $2^{\circ} 23^{\prime}-2^{\circ} 39^{\prime}$ east, hyper-aridity, extreme temperatures and scarce precipitations (around $10 \mathrm{~mm}$ ) are predominant features throughout the years; maximum temperatures can exceed $50^{\circ} \mathrm{C}$ during exceptional heat-wave event. Average duration of insulation is generally above $3000 \mathrm{~h}$ per year and, relative humidity is particularly low, especially in summer where it falls below $5 \%$ (Capot-Rey, 1946; Boulghobra, Hadri \& Bouhana, 2014).

The geomorphology of In-Salah consists of two main and distinct features: (1) the Tademait plateau in the north (about $600 \mathrm{~m}$ of average altitude) which is composed essentially of the continental tertiary and the lower Cretaceous, namely the sand, clay and sandstone (Follot \& Lefrane, 1951); (2) the plain further south (about $280 \mathrm{~m}$ ) is mostly consisting of the late quaternary namely the coarse quartz (Reg) and sand materials (Erg Sidi Moussa). The Tademait plateau is gradually linked to the plain through intermittent watercourses (e.g. Oued Souf, Oued Rokna and Oued El-Hadjadj) which flow toward the intermittent salt lakes in the south (e.g. Sebkha Ez'Zebbara) (Fig. 1). 


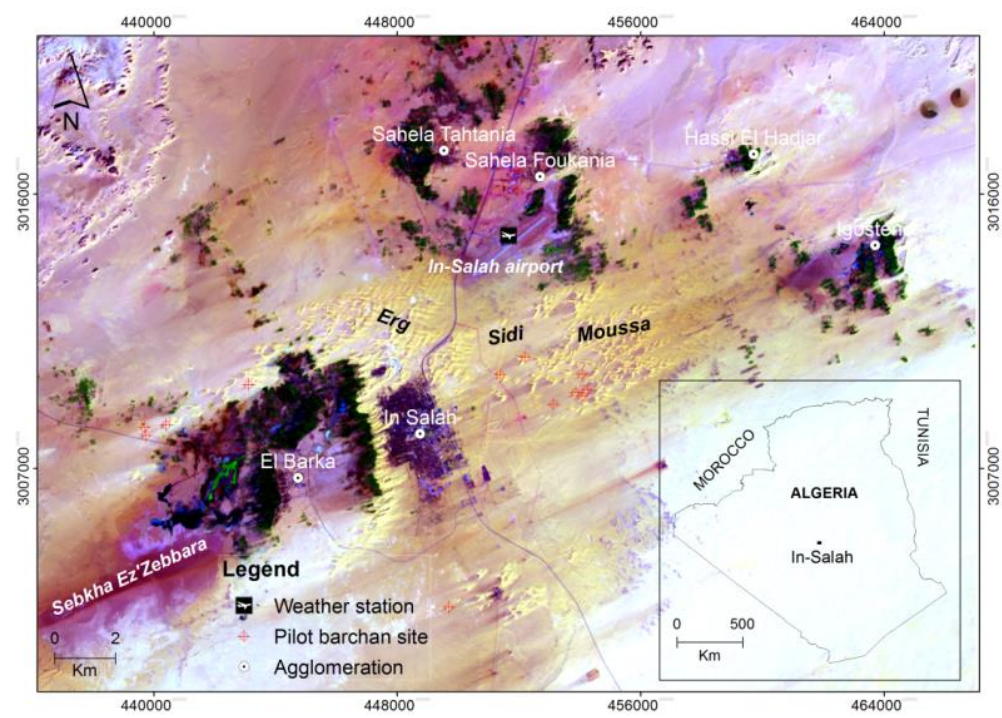

Fig. 1 Location map of the study area, based on the RGB: 652 color composite of Landsat 8 OLI image dated 2016 (www.usgs.gov); this band combination allows visualizing the sand dunes in yellow color (Projection system UTM, zone 31)

\subsection{Barchan dune morphology and migration}

The morphological characterization of barchan dune consists on measuring its dimensions, namely the length of the windward slope (a), horn-to-horn width (c), height (H) and the a/c (length/width) ratio (Fig. 2A). Actually, Bourke and Goudie (2009) after Long and Sharp (1964) suggested classifying the barchan form depending on the $(\mathrm{a} / \mathrm{c})$ as: Slim (0.125-0.375); Normal (0.376-0.625); Pudgy (0.626-0.875) and Fat (0.876-1+).

Twelve individual barchan dunes in the Erg Sidi Moussa dunefield have been chosen for morphological investigation (Fig. 1), by considering the criteria of size and representative spatial distribution throughout the dunefield. For each selected barchan, the parameters (a), (b), (c), (h) and (a/c) ratio were measured, and barchan were morphologically classified. Results are summarized in Table $\mathbf{1 .}$

In this research, determination of barchan dune migration rate and direction had been conducted using very fine resolution imagery $(2 \mathrm{~m})$ of the satellites Pléiades (provided by Google Earth) dated January 5, 2013 and February 3, 2016, using the point-to-point geocorrelation (Abou El-Magd, Hassan \& Arafat, 2013; Hamdan, Refaat \& Abdel Wahed, 2016; Boulghobra, 2016). Under a GIS software environment, bi-dated images corresponding to the processed barchans have been subjected to geometric correction, according to the Universal Transverse Mercator projection system and using at least 4 ground control points; true-color images were saved as false-color Geotiff format using the linear stretch algorithm and thus, to improve the aspect and allow the visual discrimination when superposing. As well, barchan dune outlines were traced for each image and saved as a shape file.

Figures 2B and 2C illustrate the experienced method which consists in tracing control points in specific sites on the barchan outline for each image (2013 and 2016); the migration distance of each barchan dune (D) in meter is equal to the averaged length of lines that connecting every two corresponding points; the obtained migration distance which refers to the whole period $(2013$ - 2016) was averaged to express the yearly 
movement rate for each barchan dune (m/year); also, the barchan movement direction (A) in degree clockwise from north is automatically extracted, the barchan migration rate and direction are expressed by the following equations:

$$
\begin{aligned}
& D=\sqrt{\left(y_{2}-y_{1}\right)^{2}+\left(x_{2}-x_{1}\right)^{2}} \\
& A=a \tan \left(\left(y_{2}-y_{1}\right)\right) /\left(\left(x_{2}-x_{1}\right)\right)
\end{aligned}
$$
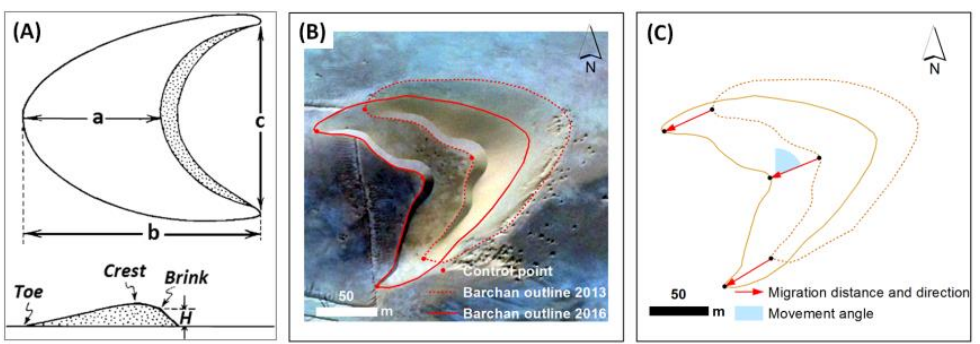

Fig. 2 (A) Schematic diagram showing the main morphometric parameters of a barchan dune; (B) Superposing of 2013's and 2016's satellite images, associated with corresponding control points; (C) Vector diagram showing the distance, direction and angle of barchan migration

\section{RESULTS AND DISCUSSION}

The investigated barchan dunes in the Erg Sidi Moussa are exhibiting a large range of morphological parameters (Table 1). They vary in height from 6 to $22 \mathrm{~m}$ with an average of $13 \mathrm{~m}$; the length of the windward slope ranges from 73 to $173 \mathrm{~m}$ (97 m average), whereas the horn-to-horn width is ranging from 70 to $336 \mathrm{~m}$ averaging $159 \mathrm{~m}$. Consequently, the average $\mathrm{a} / \mathrm{c}$ ratio is about 0.659 with a minimum of 0.481 and 1.100 maximum.

Table 1. Recapitulative of the barchans morphological features: height $\mathrm{H}$, length of the windward slope a, width $\mathrm{c}$ and barchan form; in addition to the migration rate (D) in $\mathrm{m} / \mathrm{year}$ and movement angle $(A)$ in degree azimuth

\begin{tabular}{|c|c|c|c|c|c|c|c|}
\hline Barchan & $\mathrm{H}(\mathrm{m})$ & $\mathrm{a}(\mathrm{m})$ & $\mathrm{c}(\mathrm{m})$ & $\mathrm{a} / \mathrm{c}$ & Form * & $\mathrm{D}$ & $\mathrm{A}$ \\
\hline 1 & 15 & 96 & 184 & 0,522 & Normal & 14 & 71 \\
\hline 2 & 11 & 82 & 94 & 0,872 & Pudgy & 15 & 76 \\
\hline 3 & 15 & 75 & 135 & 0,556 & Normal & 14 & 68 \\
\hline 4 & 11 & 73 & 141 & 0,518 & Normal & 18 & 67 \\
\hline 5 & 18 & 100 & 208 & 0,481 & Normal & 13 & 78 \\
\hline 6 & 22 & 173 & 336 & 0,515 & Normal & 7 & 72 \\
\hline 7 & 6 & 77 & 70 & 1,100 & Fat & 23 & 66 \\
\hline 8 & 12 & 96 & 164 & 0,585 & Normal & 12 & 71 \\
\hline 9 & 13 & 120 & 159 & 0,755 & Pudgy & 16 & 69 \\
\hline 10 & 8 & 106 & 179 & 0,592 & Normal & 10 & 69 \\
\hline 11 & 13 & 76 & 135 & 0,563 & Normal & 13 & 94 \\
\hline 12 & 11 & 92 & 108 & 0,852 & Fat & 15 & 64 \\
\hline Average & 13 & 97 & 159 & 0,659 & Normal & 14 & 72 \\
\hline
\end{tabular}

The morphological classification of barchan dunes, according to Bourke \& Goudie (2009) revealed that normal dunes are obviously the most prominent representing about 67 
$\%$ from the 12 investigated barchans, they occur in different and unspecified areas throughout the dunefield. Pudgy and fat dunes are less common (17\% for each variety), they occur in the front of the dunefield in the downwind of significant sand supply and influx, especially under low wind shear velocity which increases the accumulation process (Parteli, Durán \& Herrmann, 2007). Differently to the other barchan varieties, slim barchan has not been encountered among the investigated dunes.

The application of point-to-point geocorrelation on fine resolution imagery allowed accurately measuring the barchan movement rate and direction; results showed that the movement rate ranged from 7 to $23 \mathrm{~m} /$ year (14 m/year average) during the period Jan. 5 , 2013-Feb. 3, 2016. Also, the movement angle ranged from 64 to 94 degrees (72 average), this range of values fit with the barchans orientation, which is uniformly toward the westsouthwest, in accordance with the prevailing wind direction and the resultant drift direction.

In addition to wind regime and energy, sand availability, vegetation and topography, barchan movement is often depending on its dimensions especially the height of the slipeface, considered as the most determining factor (Long \& Sharp, 1964). The test of the relationship between dune morphology and movement revealed that barchan movement rate is inversely proportional to the height and width (Fig. 4); barchans with smallest heights such as barchan 4 and barchan 7 (11 and $6 \mathrm{~m}$ respectively) are marked with greatest movement rates (18 and $23 \mathrm{~m} / \mathrm{yr}$, respectively), whereas barchan 6 characterized by significant height $(22 \mathrm{~m})$ was marked by lower migration rate $(7 \mathrm{~m} / \mathrm{yr})$. Besides, barchans of larger width such as barchan $6(336 \mathrm{~m} ; 7 \mathrm{~m} / \mathrm{yr})$ are moving much slowly than less-sized ones (e.g. barchan 7: $70 \mathrm{~m} ; 23 \mathrm{~m} / \mathrm{yr}$ ).
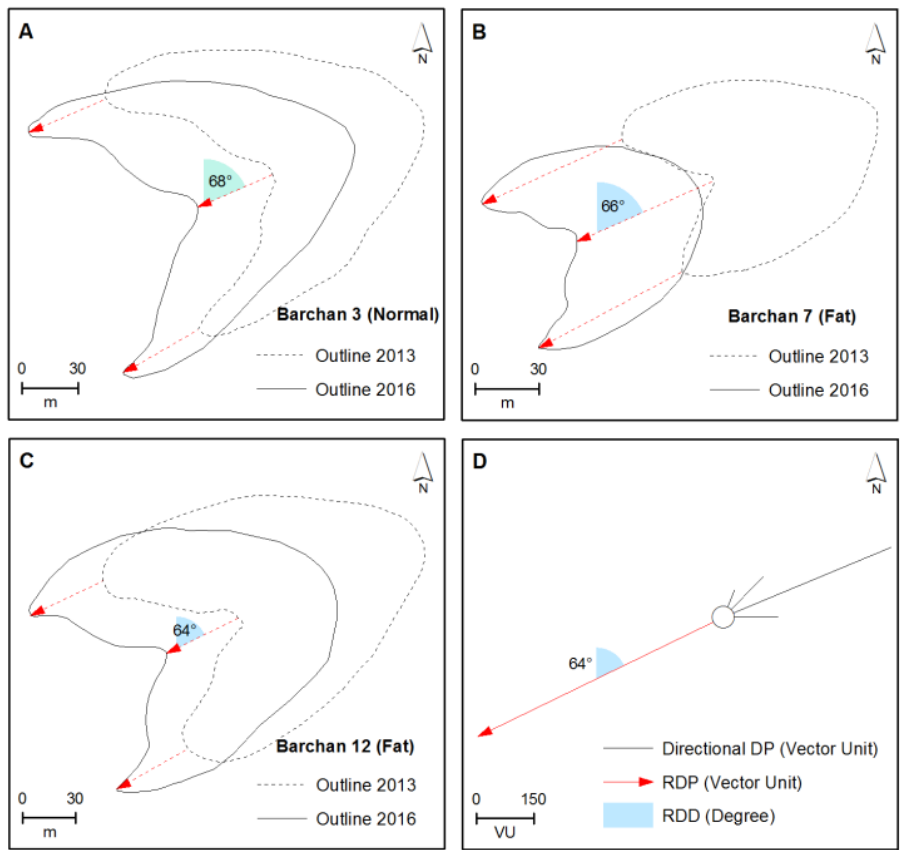

Fig. 3 (A), (B) and (C) correspond to vector diagrams showing the migration distance and direction for 3 barchans during the period Jan. 5, 2013 to Feb. 3, 2016; (D) is the sand rose diagram showing the magnitude and direction of sand transport (In-Salah station, Jan. 5, 2013 to Feb. 3, 2016). Note that measured movement angle is fitting with the resultant drift direction (estimated angle of migration) 
The Erg Sidi Moussa area is a high energy wind environment producing significant volumes of transported sand, estimated to be $50 \mathrm{~m}^{3}$ of sediments per 1 meter of land width per year (for the period 2013-2016), where sand transport and barchan migration are mainly controlled by a strong and steady uni-modal wind regime directed to the west-southwest areas. Downwind, the city of In-Salah constitutes a real obstacle for moving sediments and dunes, and, consequently, is facing the perceptible and continuous impacts of encroaching sands (Dubost, 2002; Boulghobra, Hadri \& Bouhana, 2014). Damages are particularly serious including abandoned residences, palm-date groves, pipes and multiple roads. As shown in figure 5, several hectares of palm-date have been lost due to sand accumulation between 1987 and 2016, while the urban built steel extending over risky areas from $3 \mathrm{~km}^{2}$ in 1987 to $9 \mathrm{~km}^{2}$ at present, which could increase the vulnerability and lead to more damages.

To mitigate damages, the establishment of dune fixation techniques upwind (north east) is required; in parallel, the direction of sand transport and dune movement should be considered in urban, socioeconomic, and agricultural future projects.
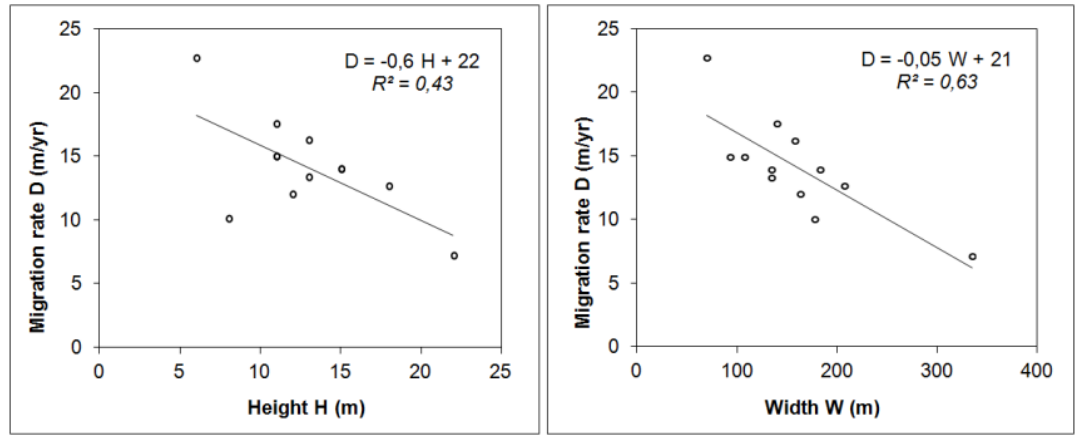

Fig. 4 Relationship between the barchan migration rate $\mathrm{D}$ and barchan height $\mathrm{H}$ (left) and barchan

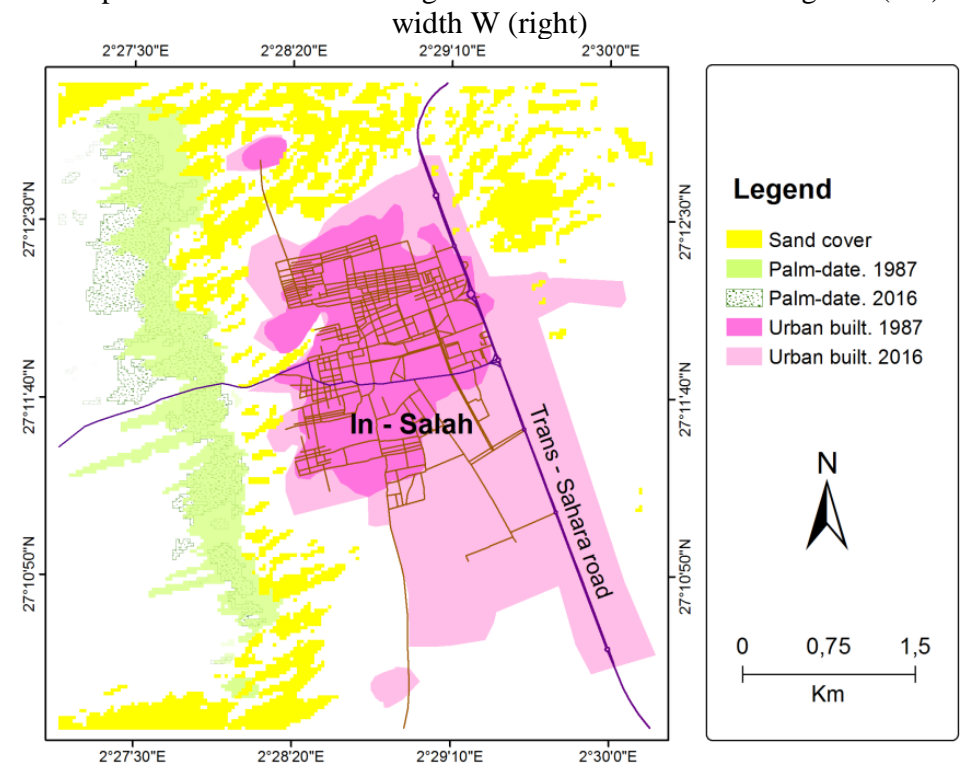

Fig. 5 Vector map showing the impact of accumulating-sand on urban area and palm-grove. Note that the built area extends toward risky sites, and that palm-date regresses toward the southwest 


\section{CONCLUSION}

This paper interested in determining the morphological characteristics of some barchan dunes in the Erg Sidi Moussa dunefield (near In-Salah, Algeria), as well as investigating their migration rate and direction for a better understanding of the risk of encroaching sand in the area of In-Salah. Results showed that the barchan height ranges from 6 to $22 \mathrm{~m} \mathrm{(13} \mathrm{m}$ average), the average of the windward slope length ranges from 73 to $173 \mathrm{~m}$ and the hornto-horn width ranges from 70 to $336 \mathrm{~m}$. Based on the length/width ratio, the morphological classification of barchans dunes, according to Bourke \& Goudie (2009) revealed that normal barchan is the most prominent variety in the studied dunefield, whereas pudgy and fat dunes are less common. Barchan migration rate and direction have been accurately measured based on fine resolution imagery and using a GIS-based approach, results showed that the average movement rate is about $14 \mathrm{~m} / \mathrm{yr}$ during the period 2013-2016, and the movement angle is $64^{\circ}$ in well accordance to prevailing wind and sand transport direction, which are directed toward the west-southwest. Simple regression tests revealed that dune migration rate is inversely proportional to the barchan dimensions, namely the height and width, and small dunes are generally moving faster than bigger ones. When migrating, these dunes are accumulating downwind in built areas, palm-date plantations and socioeconomic infrastructures, leading to serious and perceptible damages. Thereby, it is highly recommended that dune fixation techniques be established in the sand-source areas, and that land-use be controlled in order to prevent construction on prone areas.

\section{R E F E R E N C E S}

Abou El-Magd, I., Hassan, O. \& Arafat, S. (2013) Quantification of sand dune movements in the south western part of Egypt, using remotely sensed data and GIS. J Geogr Inf Syst, 5, 498-508;

Al-Dousari, A.M. \& Pye, K. (2005) Mapping and monitoring of dunes in Northwestern Kuwait. Kuwait J Sci Eng, 32, 119-134;

Bouhata, R. \& Kalla, M. (2014) Mapping of environmental vulnerability of desertification by adaptation of the MEDALUS method in the endoreic area of Gadaine (eastern Algeria). Geographia Technica, 9, 1-8;

Boulghobra, N. (2016) Climatic data and satellite imagery for assessing the aeolian sand deposit and barchan migration as a major risk sources in the region of In-Salah (Central Algerian Sahara). Arab J Geosci, 9, 1-15;

Boulghobra, N., Hadri, T. \& Bouhana, M. (2014) Using Landsat imagery for monitoring the spatiotemporal evolution of sanding in drylands, the case of In-Salah in the Tidikelt (southern Algerian Sahara). Geographia Technica, 9, 1-9;

Bourke, M.C. \& Goudie, A.S. (2009) Varieties of barchan form in the Namib Desert and on Mars. Aeolian Res, 1, 45-54;

Breed, C.S., Fryberger, S.G., Andrews, S., McCauley, C., Lennartz, F., Gebel, D. \& Horstman, K. (1979) Regional studies of sand seas, using Landsat (ERTS) imagery. In: McKee, E.D. (eds.) A study of global sand seas, geological survey professional paper, US government printing office, Washington, pp. 305-398;

Capot-Rey, R. (1946) Études récentes sur le climat de l'Afrique du nord et du Sahara. Annales de Géographie, 297, 39-48;

Dubost, D. (2002) Ecologie, Aménagement et développement agricole des oasis algériennes. Centre de Recherche Scientifique et Technique sur les Régions Arides (ed.), Biskra, Algérie

Finkel, H.J. (1959) The barchans of southern Peru. J Geol, 67, 614-647; 
Follot, J. \& Lefrane, J. (1951) Carte géologique de reconnaissance du Sahara, In-Salah. Centre Rech Sah, Paris;

Fryberger, S.G. \& Dean, G. (1979) Dune forms and wind regime. In: McKee, E.D. (eds.) A study of global sand seas, geological survey professional paper, US government printing office, Washington, pp. 137-170;

Hamdan, M.A., Refaat, A.A. \& Abdel Wahed, M. (2016) Morphologic characteristics and migration rate assessment of barchan dunes in the Southeastern Western Desert of Egypt. Geomorph, 257, $57-74$;

Khalaf, F.I. \& Al-Ajmi, D. (1993) Aeolian processes and sand encroachment problems in Kuwait. Geomorph, 6, 111-134;

Lancaster, N. (2009) Dune morphology and dynamics. In: Parsons, A.J. \& Abrahams, A.D. (eds) Geomorphology of desert environments, $2^{\text {nd }}$ ed. Springer Science + Business Media B.V., Springer Netherlands, pp. 557-595;

Long, J.T. \& Sharp, R.P. (1964) Barchan-dune movement in Imperial Valley, California. Geol Soc Am Bull, 75, 149-156;

McKee, E.D. (1979) A Study of Global Sand Seas. Prof. Pap. U.S. Geol. Survey, Washington, 1052

Parteli, E.J.R., Durán, O. \& Herrmann, H.J. (2007) Minimal size of a barchan dune. Phys Rev E, 75, $1-10$;

Sauermann, G., Rognon, P., Poliakov, A. \& Herrmann, H.J. (2000) The shape of the barchan dunes of Southern Morocco. Geomorph, 36, 47-62

Tsoar, H. (2001) Types of aeolian sand dunes and their formation. Geomorphological Fluid Mechanics, 582, 403-429

Tsoar, H. (2004) Sand dunes. In: Hillel, D. (ed) Encyclopedia of Soils in the Environment. Elsevier, Oxford, pp. 462-471

Verlaque, C. (1958) Les dunes d'In-Salah. Trav. Inst. Rech. Sah. Alger, 17, 13-58

Warren, A. \& Knott, P. (1979) Desert dunes: a short review of needs in desert dune research and a recent study of micrometeorological dune initiation mechanisms. In: Brookfield, M.E. \& Ahlbrandt, T.S. (eds) Eolian sediments and processes. Elsevier Science Publishers B.V., Amsterdam 